\title{
Finite Element Analysis of a Ribbed Roofing Panel under Static Flexure
}

\author{
Okafor C. Vincent
}

\begin{abstract}
This study focuses on analyzing the response of a typical ribbed aluminum panel under flexure. A three dimensional finite element model was developed to stimulate the static flexure behavior. The model is a $2.0 \mathrm{~m}$ (length) $\times 1.0 \mathrm{~m}$ (width) $\times 0.005 \mathrm{~m}$ (Thickness) with a rib height of $0.038 \mathrm{~m}$, crest width of $0.019 \mathrm{~m}$ and pan distance at $0.055 \mathrm{~m}$ between intermediate ribs. The load deflection response of the aluminum panel under different flexural loading condition was stimulated. The linear material properties, displacement, stress and strain captured were discussed under static conditions. From the result obtained, the maximum uniformly distributed load carrying capacity of the ribbed aluminum roofing panel under flexure, considering the linear material properties is $665 \mathrm{~N}$.
\end{abstract}

Index Terms-Finite Element Analysis; Aluminum Ribbed Roofing Panel; Flexure; Ultimate Carrying Capacity; Von Mises Stress; Principal Stress.

\section{INTRODUCTION}

Roof is one of the main building elements, consumes about $25 \%$ of the total expenditure of construction [1]. In recent years, aluminum was not a popular roofing material due to cost reasons and because of concern about structural limitations of aluminum. Thereby, making asbestos cement based roofing gain more popularity in developing countries such as Nigeria despite the fact that it has been banned in other developed countries having been linked to the sources of many diseases. However, recent innovations have resolved the structural problems and cost problems associated with aluminum roofing [2].

Corrugated roofing system is most preferred and widely used in rural and industrial areas because it allows mechanical and dry consumption methods to cover large areas without the need for ceiling compounds to prevent leakage [3].

Aluminum roofing panels are very durable and extremely corrosion resistant-a significant advantage in coastal areas and areas with a great precipitation or acidic rainfalls.
Published on June 25, 2018

C. V. Okafor, Ms.c Department of Building, Nnamdi Azikiwe University Nigeria (e-mail: chinedumokafor117@yahoo.com).

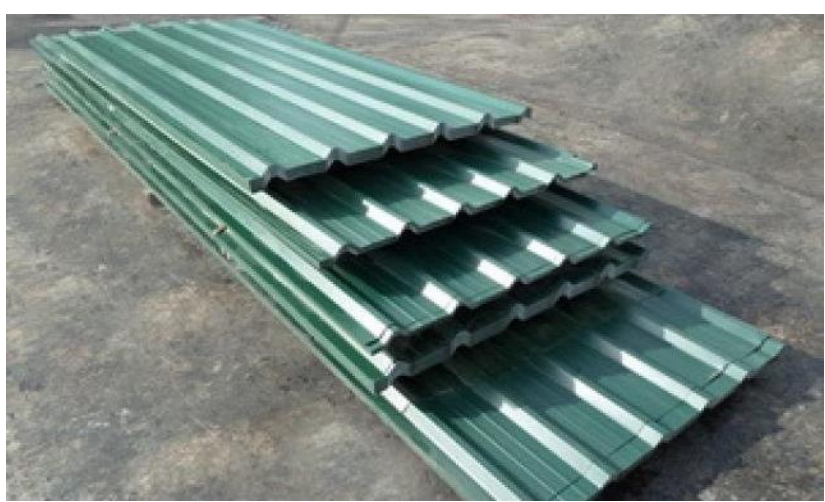

Fig. 1. Ribbed Aluminum Roofing Panel

In spite of these benefits of using aluminum roofing, aluminum has lower strength than steel. The density of aluminum is approximately 2.6 to $2.8 \mathrm{~g} / \mathrm{cm}^{3}$. i.e., approximately $1 / 3$ the density of steel.

This study analyzed a typical aluminum ribbed profiled panel under flexural loads using Finite Element Analysis so as to determine the ultimate load carrying capacity of the panel in accordance to standard and specifications in [4].According to [5], with the rapid development in computer science and numerical structural analysis technology, it has become possible to use computer-based finite element methods to determine complex stress distributions and severe shape distortion in load bearing regions so as to identify highly stressed areas where local plastic collapse and fatigue cracks may originates, and also to find the relationship between the loads and stresses at critical areas, and explain local failure mechanism.

\section{NUMERICAL ANALYSIS BY USING LISA}

Numerical methods provide a general tool to analyze arbitrary geometries and loading conditions [6]. Among the numerical methods, Finite element analysis has been extensively used with success; however, this kind of analysis consumes large investments in engineering time and computer resources and requires the generation of large sets of data in order to obtain accurate results [7].

There are three basic steps involved in this procedure,

1) Pre Processor (Building the model or modeling)

2) Solution (Applying Loads and solving)

3) Post Processor (Reviewing the result)

\section{A. Material Properties used for Modeling}

The static analysis of the ribbed aluminum panel was carried out using Lisa finite element analysis software. Lisa requires input data for material properties as follows: 
TABLE I: MATERIAL PROPERTY FOR THE FEA MODEL

\begin{tabular}{ll}
\hline \hline Alloy(AA) & EN AW-3003 \\
\hline Young Modulus & $7 \times 10^{4} \mathrm{mpa}$ \\
Poissons Ratio & 0.33 \\
Ultimate Tensile Strength & $170 \mathrm{mpa}$ \\
Yield Strength & $150 \mathrm{mpa}$ \\
Density & $2.78 \mathrm{~g} / \mathrm{cm}^{3}$ \\
Element type & Nine-Node Biquadratic \\
& quadrilateral \\
\hline \hline
\end{tabular}

The figure below is a cross section of a typical alloy EN AW-3003[A1Mn1Cu] ribbed profile sheet of size $1 \mathrm{~m}$ (width) $\times 2 \mathrm{~m} \quad$ (Length) $\times 0.005 \mathrm{~m} \quad$ (Thickness), rib height $=0.038 \mathrm{~m}$, width of crest $=0.019 \mathrm{~m}$ and Pan distance of $0.055 \mathrm{~m}$.

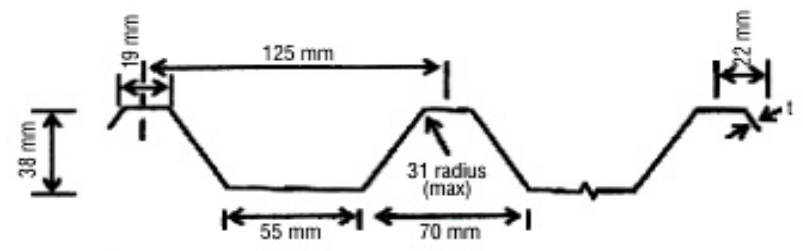

Fig. 2. Cross Section of the Panel with dimensions

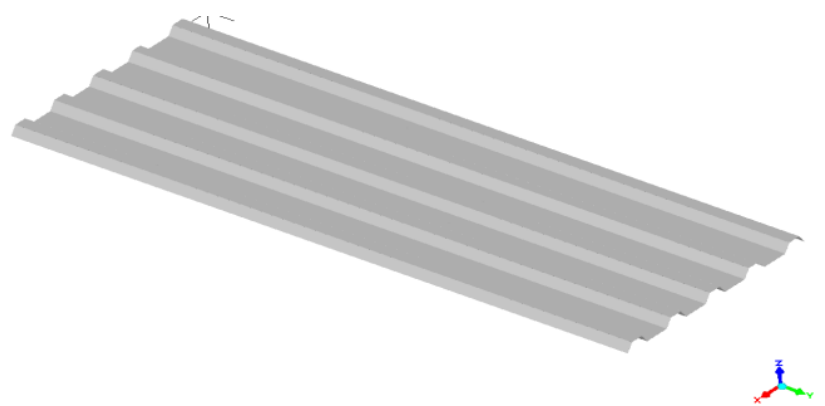

Fig. 3. FEA Model of the ribbed aluminum roofing panel showing elements surface.

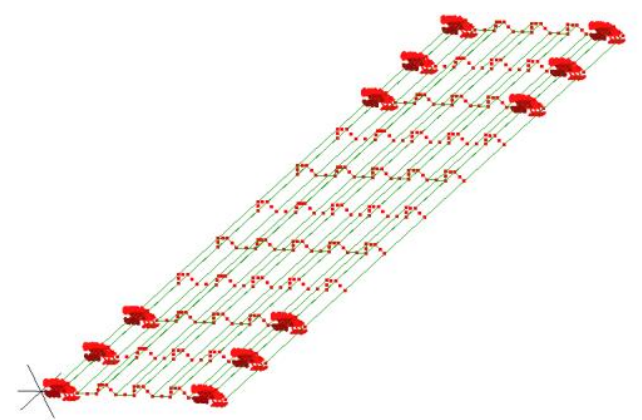

$\mathbb{2}^{2}$

Fig. 4. FEA Model of the ribbed aluminum roofing panel showing nodes and constraint

\section{B. Nine-Node Biquadratic quadrilateral element type}

In Finite element analysis, accuracy of the solution largely depends on the type of element chosen in the analysis input. For this analysis, Nine-Node Biquadratic quadrateral element type was used to define the geometry. This element is often abbreviated to Quad 9 in Finite Element Model literatures. The element has three types of shape function which are associated with corner nodes, middle nodes and centre nodes respectively. Its geometry is shown in Fig 5.

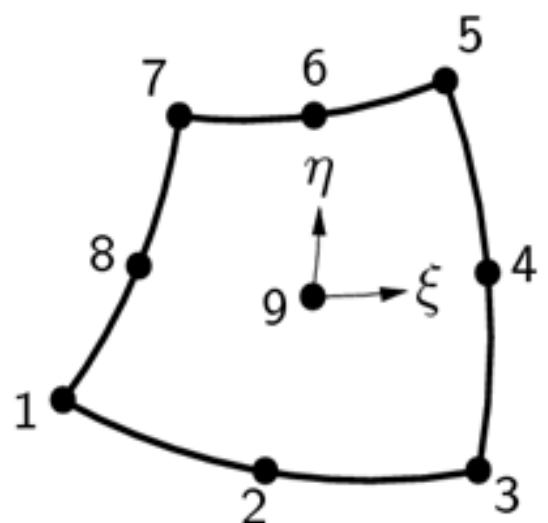

Fig. 5. Nine-Node Biquadratic quadraterial element.

\section{Boundary Condition}

The objective in this paper is to understand the mechanical behavior of the aluminum ribbed roof under flexure. The specimen was modeled with linear finite element models. The fixed support conditions are given at the ends of the panel and loading is applied at distances of $0.2 \mathrm{~m}$ each from the ends. The linear solution is carried out and the panel solution is obtained both for its node and elements.

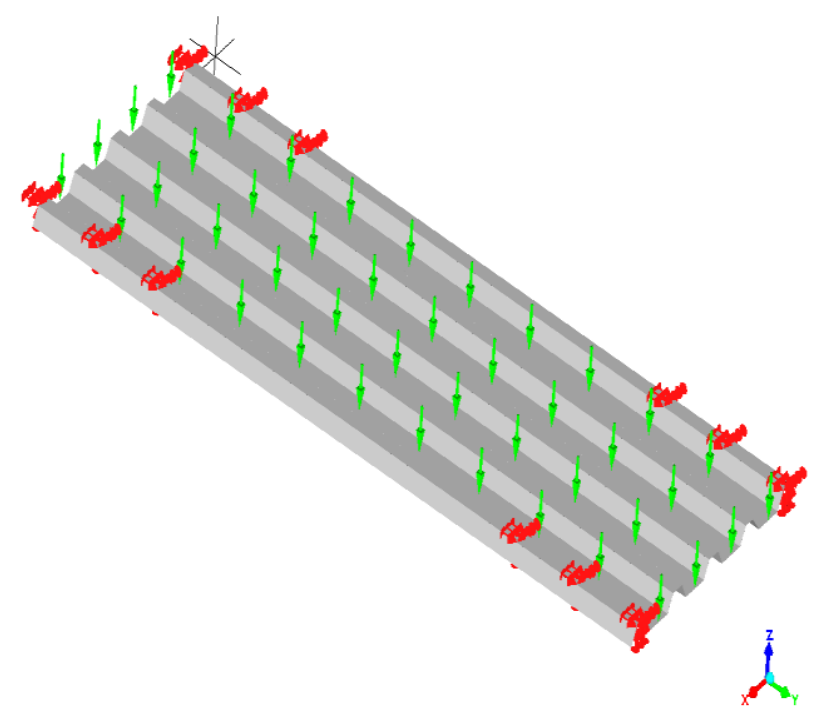

Fig. 6. FEA Model of the ribbed aluminum roofing panel subjected to varying flexural loads

\section{ANALYSIS RESULT AND DISCUSSION}

Flexural loads are applied on the panel by increasing the loads from $0 \mathrm{~N}, 100 \mathrm{~N}, 200 \mathrm{~N}, 300 \mathrm{~N}, 400 \mathrm{~N}, 500 \mathrm{~N}, 600 \mathrm{~N}$ and $665 \mathrm{~N}$. The result was obtained and virtually displayed in the form of Von-mises stresses and principal stresses. The deformed shaped of the panel under the flexural loads was displayed in Fig 7. 


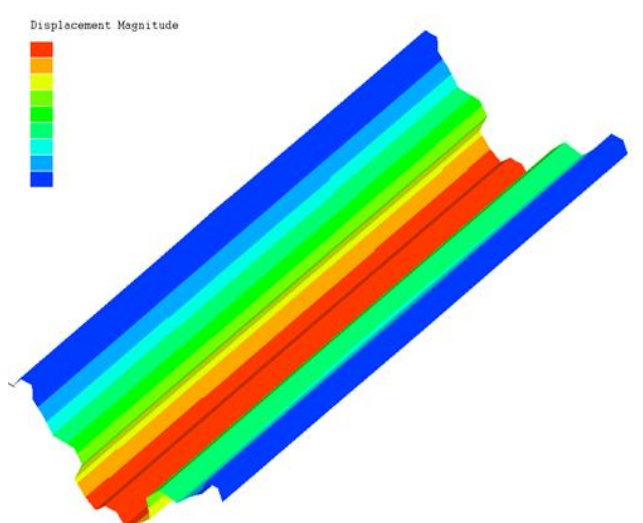

K.

Fig. 7. Deformed shape of the ribbed aluminum panel subjected to flexure

\section{A. Case 1: For Flexural Load of 100N}

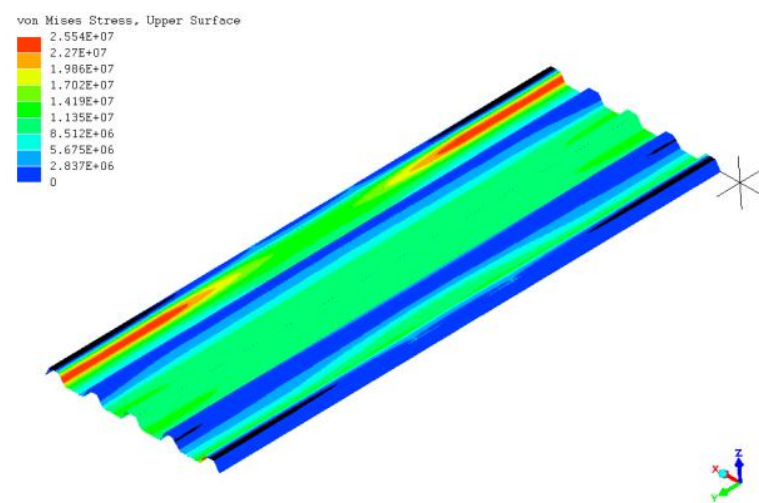

Fig. 8. Von Mises stress of the ribbed roofing panel

Von mises stresses of the Roofing panel for characteristic flexural load of $100 \mathrm{~N}$ was shown in Fig. 8. The largest stress occurs at the end of the panel, and its value was $25.54 \mathrm{Mpa}$. According to [4], the minimum to maximum yield tensile stress of Alloy EN AW- 3003 Aluminum panel is 170mpa. From the result shown in Fig. 8, the maximum von mises stress was $25.54 \mathrm{mpa}$ which is smaller than $170 \mathrm{mpa}$.

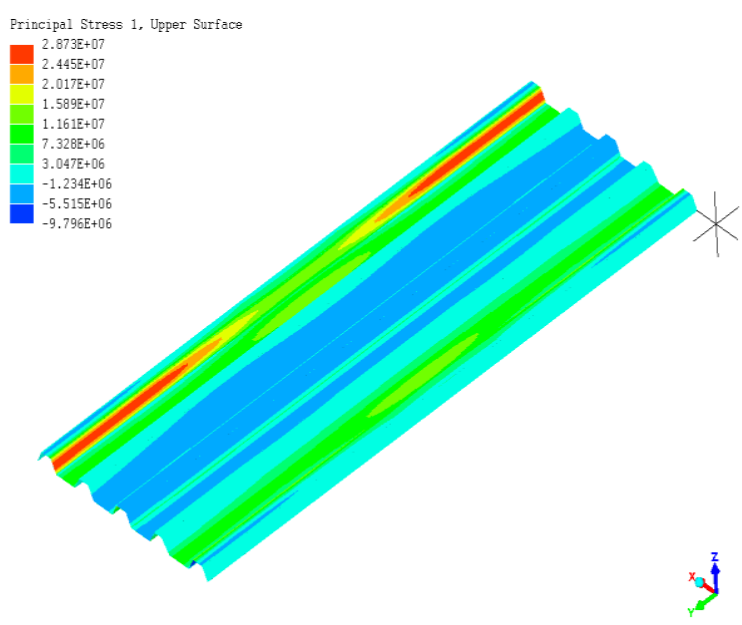

Fig. 9. Principal stress 1 of the ribbed roofing panel.

According to maximum principle stress theory, failure will occur when the maximum principal stress in a system reaches the values of the maximum strength at elastic limit in simple tension test. From the image above, it can be deduced that the maximum normal stress that occurred at the major principal plane was located at the end of the panel with value of $28.73 \mathrm{MPa}$. In [4], the ultimate yield strength of Alloy EN AW-3003 aluminum panel is 150Mpa. $28.73 \mathrm{MPa}$ is less than $150 \mathrm{MPa}$.

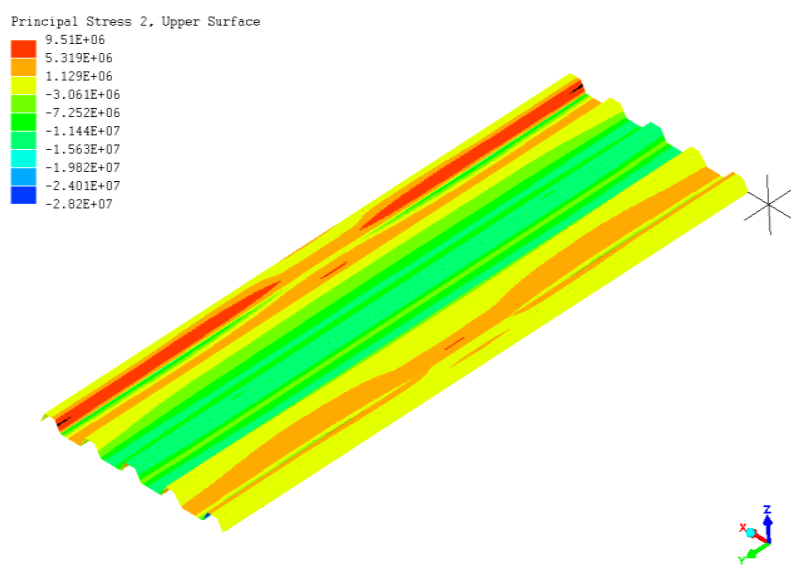

Fig. 10. Principal Stress 2 of the ribbed roofing panel.

The maximum normal stress that occurs at the principal plane 2 is located at the region where the fasteners are attached with maximum principal stress of $9.51 \mathrm{MPa}$. This principal stress was lower than the ultimate yield strength of the roofing panel.

\section{B. Case 2: For Flexural Load of $200 N$}

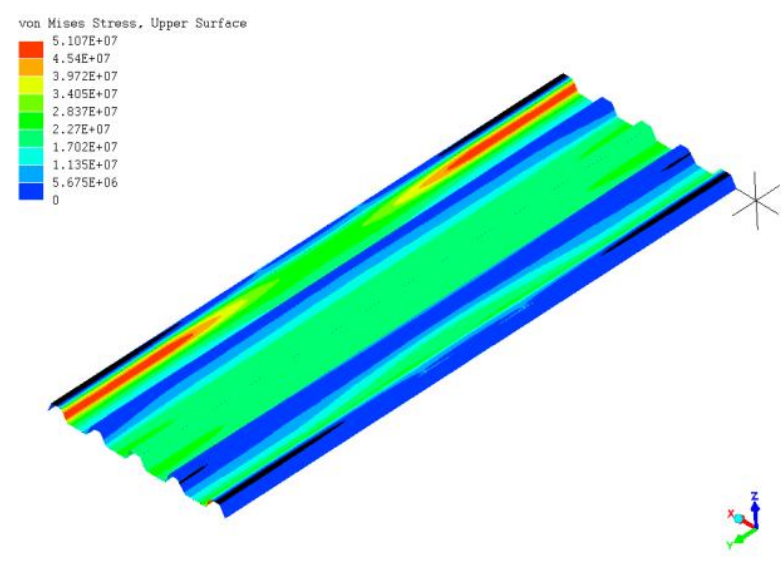

Fig. 11. Von mises stress of the ribbed roofing panel.

The largest stress was recorded at the end of the panel with a value of $51.07 \mathrm{MPa}$ knowing that the panel was supported at the ends. This stress is less than the ultimate tensile strength of $170 \mathrm{mpa}$. 


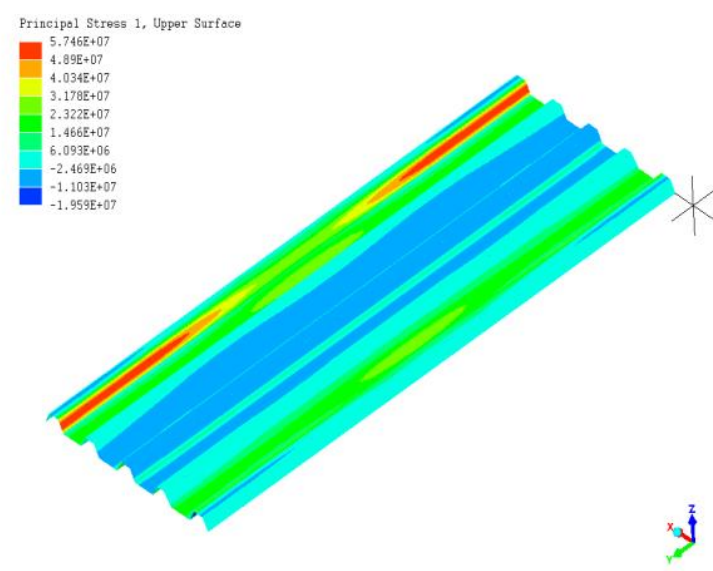

Fig. 12. Principal stress 1 of the ribbed roofing panel.

From the principal stress contour diagram in Fig. 12, the maximum normal stress acting on the major principal plane of the panel occurred at the end of the panel with a value of $57.46 \mathrm{MPa}$. This value was smaller than $150 \mathrm{mpa}$.

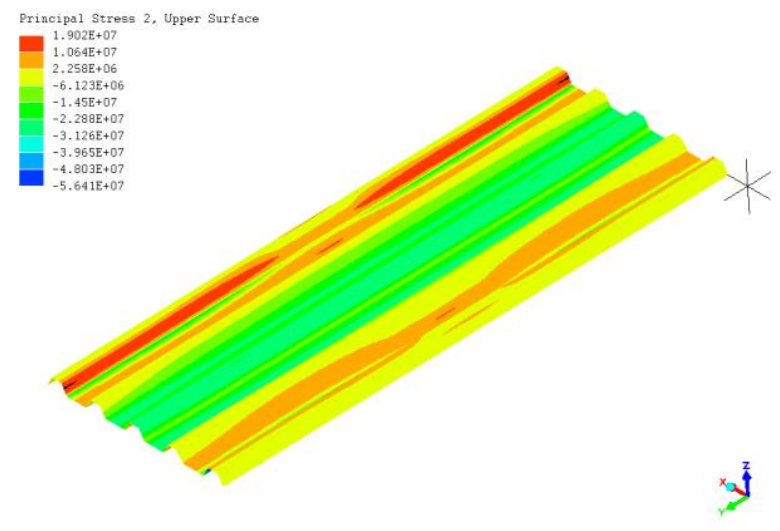

Fig. 13. Principal stress 2 of the ribbed roofing panel.

According to [4], the stress limit for Alloy EN AW3003Aluminium panel is $150 \mathrm{mpa}$. From the result shown in Fig. 13, Maximum principal stress $=19.02 \mathrm{MPa}$, which was smaller than $150 \mathrm{mpa}$.

\section{Case 3: For Flexural Load of 300N}

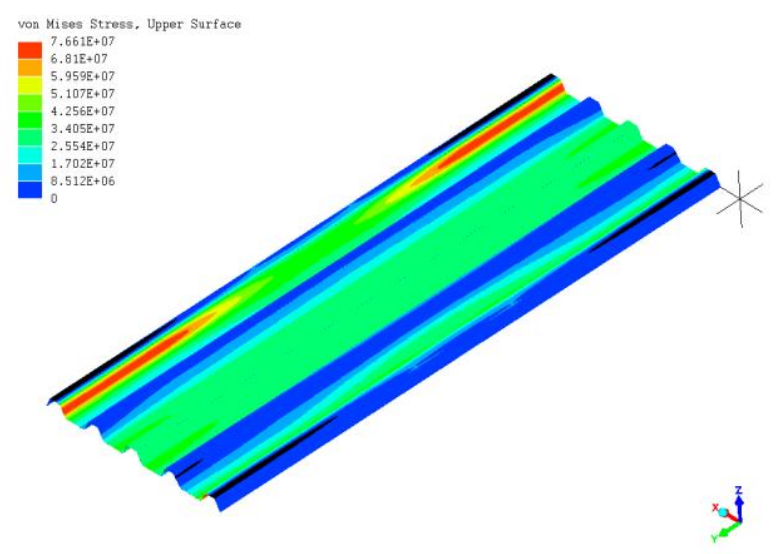

Fig. 14. Von mises stress of the ribbed roofing panel.

From the contour diagram in Fig. 14, the maximum von mises stress was located at the end of the panel. Also because the panel was supported at the 4 sides, the roofing sheet was deformed inwards from the centroids when flexural load was applied on the panel. The value of this maximum von mises stress was $76.61 \mathrm{MPa}$ which was smaller than 170Mpa.

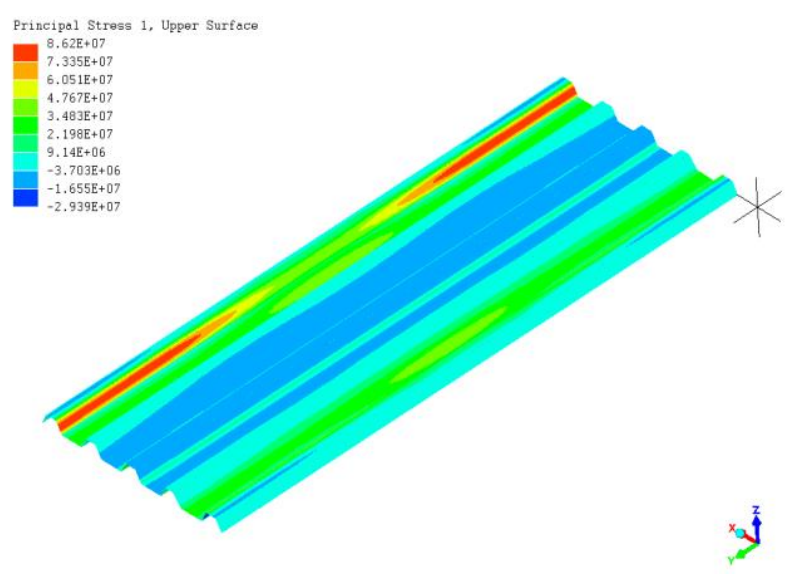

Fig. 15. Principal stress 1 of the ribbed roofing panel.

Major Principal Stress=86.2MPa which was lower than $150 \mathrm{MPa}$

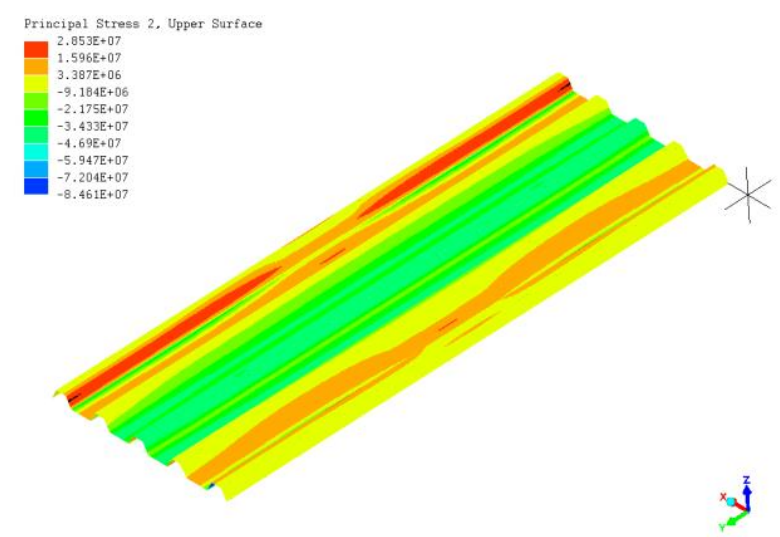

Fig. 16. Principal stress 2 of the ribbed roofing panel.

Major Principal stress $2=28.53 \mathrm{MPa}$ which was also lower than $150 \mathrm{MPa}$.

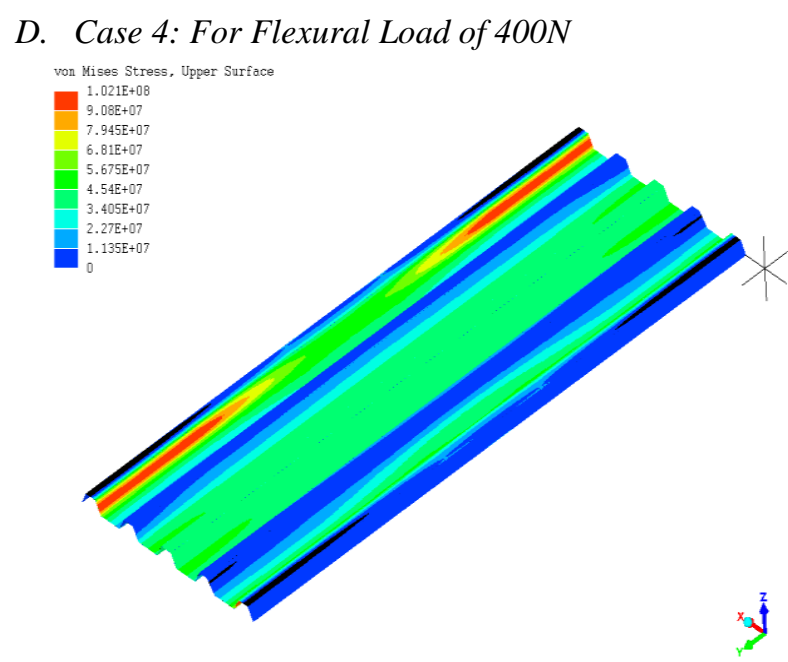

Fig. 17. Von mise stress of the ribbed roofing panel.

From the contour diagram in Fig. 17, The value of this maximum von mises stress was at $102.1 \mathrm{MPa}$ which is smaller than 170MPa. 


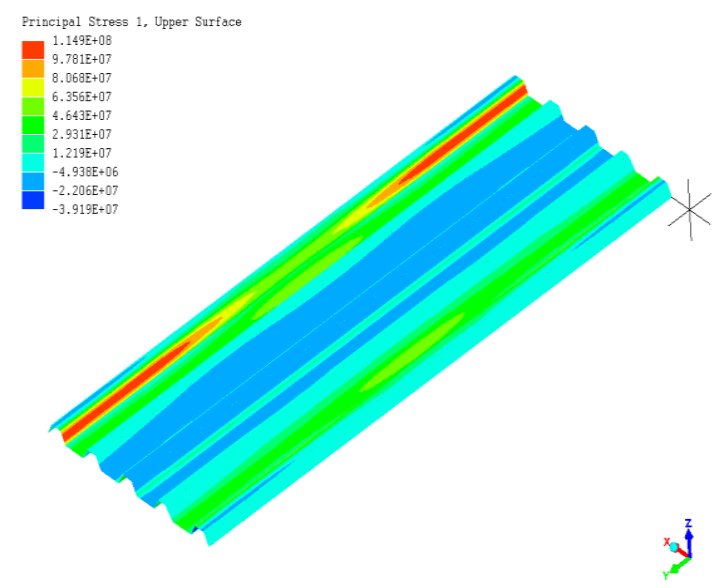

Fig, 18. Principal stress of ribbed roofing panel.

Major Principal Stress $=114.9 \mathrm{MPa}$ which was also lower than $150 \mathrm{MPa}$

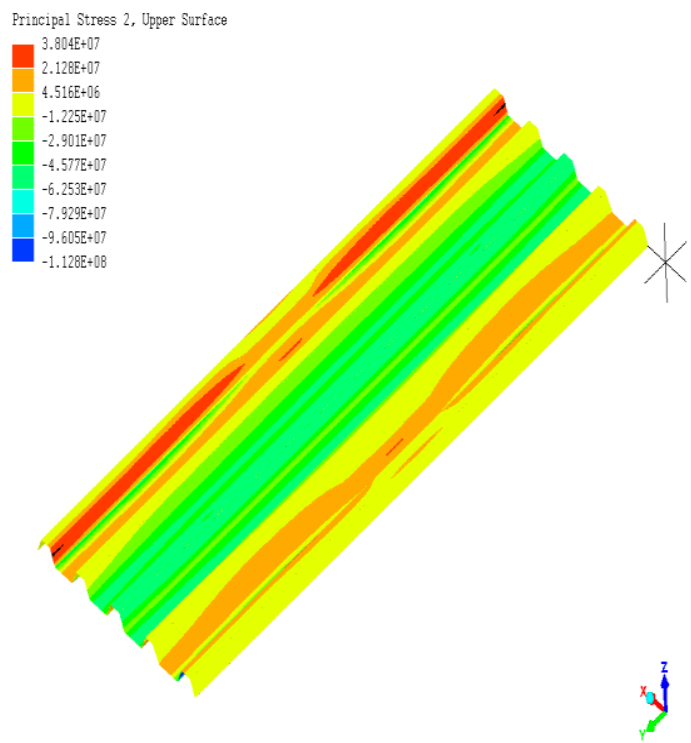

Fig. 19. Principal stress 2 of the ribbed roofing panel.

Major Principal Stress=38.04MPa which was lower than 150mpa.

E. Case 5: For Flexural Load of $500 N$

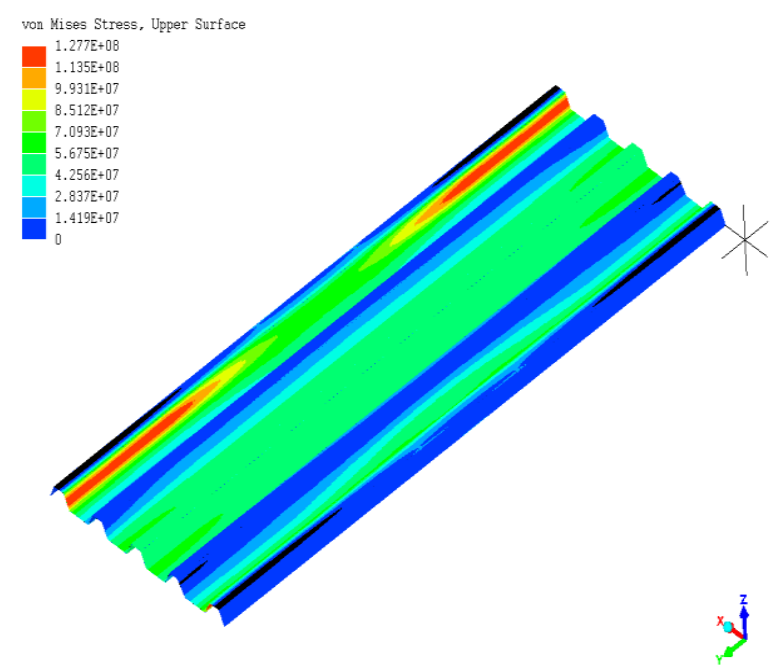

Fig. 20. Von mises stress of the ribbed roofing panel.
Fig. 20 displayed the contour diagram of maximum von mises stress on the roofing panel. The value of this maximum von mises stress was at $127.7 \mathrm{MPa}$ which is smaller than 170MPa.

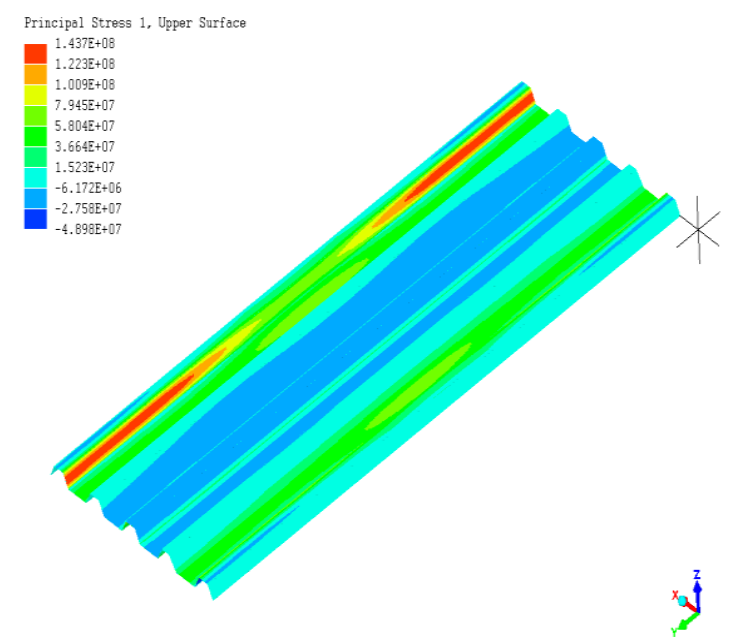

Fig. 21. Principal stress 1 of the ribbed roofing panel.

From Fig 21, the maximum stress on the major principal plane is occurred at a value of $143.7 \mathrm{Mpa}$. This value however is smaller than yield stress value of alloy AW EN3003 as specified in [4].

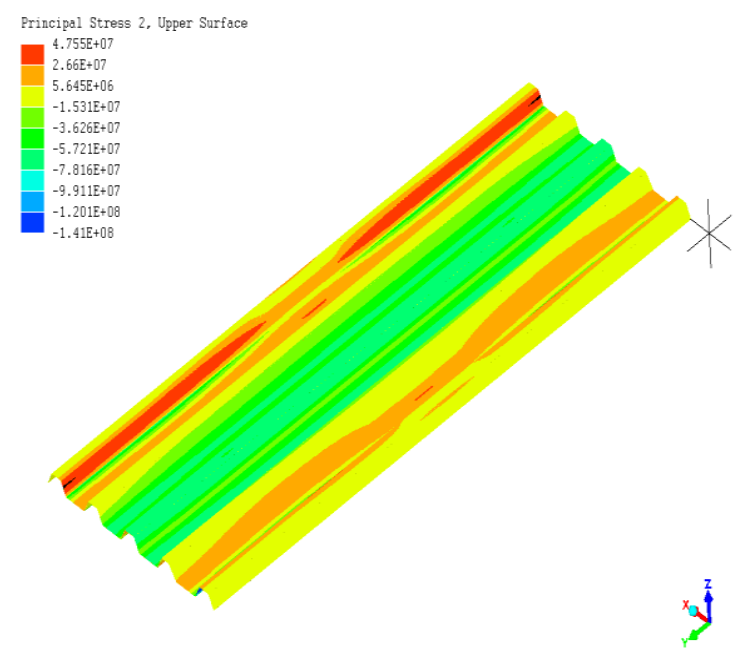

Fig. 22. Principal stress 2 of the ribbed roofing panel.

The Maximum principal stress value for the major principal plane according to the contour diagram above is 47.55MPA which is also less than 150mpa.

F. Case 6: For Flexural Load of $665 \mathrm{~N}$ 


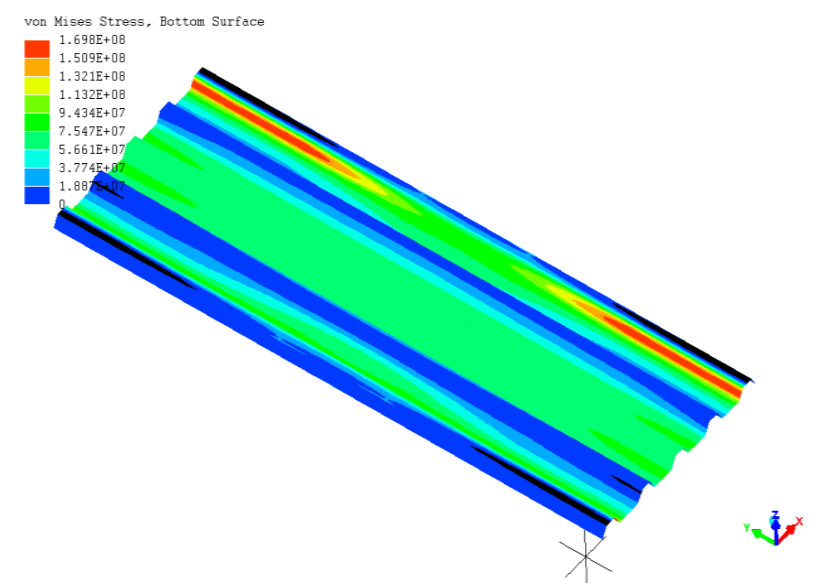

Fig. 23. Von mises stress of the ribbed roofing panel.

A design will fail if the maximum value of von mises stress induced in the material is more than the strength of the material.

The maximum value of the von mises stress when the roofing panel is subjected to a uniformly distributed flexural load of $665 \mathrm{~N}$ is $169.8 \mathrm{MPA}$. Although this value is lower than the yield strength of the aluminum alloy AW EN-3003 series as specified in [4], addition of further load will induce the roofing panel to tend to plastic deformation.

Therefore, the stress intensity shows that $665 \mathrm{~N}$ is the ultimate load carrying capacity of the roofing panel.

\section{CONCLUSION}

A ribbed roofing panel was modeled and analyzed under static flexure by increasing the loads from $100 \mathrm{~N}, 200 \mathrm{~N}$, $300 \mathrm{~N}, 400 \mathrm{~N}, 500 \mathrm{~N}$ and $665 \mathrm{~N}$.
Based on the Finite element analysis of the aluminum roofing panel, the following conclusion was drawn.

The maximum uniformly distributed load carrying capacity of the ribbed aluminium profile panel under flexure with the linear material properties is $655 \mathrm{~N}$.

\section{REFERENCES}

[1]. G. Ramakrishna, T. Sundaranrajan and S. Kothandaraman. Strength of corrugations of a roofing sheets reinforced with sisal fibres. ARPN Journal of Engineering and Applied science, Vol 6,No 12,PP 2432,December 2011.

[2]. Homedoctor.net, "aluminium roofing", Quinstreet., Inc, (2018).

[3]. B. S. Santhosh, N.R. Ragharendra, J. Deepesh, S. Vishal and P. Ayush. Strength of corrugated roofing element reinforced with coir. International Research Journal of Engineering and Technology(IRJET), Vol 4, Isssue 6, PP 2371-2374, June 2017.

[4]. BS EN 485-2 2Aluminium and aluminium alloys" - Sheet, Strip and Plate, Part 2: Mechanical Properties.

[5]. S. Nalini, R.M Saravanakumar, E. Ramya and B. Karthik Finite Element Analysis of Composite Precast Roof Panel under Static Flexure. International Journal of Engineering Research and Techno $\log y(I J E R T)$ Vol 3, Issue 11, PP 707-710, November 2014.

[6]. E. Al-Momani, R. Ibrahim. Application of finite element method and design of experiments in the optimization of sheet metal blanking process. Jordan Journal of Mechanical and Industrial Engineering(JJMIE), Vol 2, No 1, PP 53-63, March 2008.

[7]. H. Andruet, "Special 2-D and 3-D Geometrically Nonlinear finite elements for analysis of Adhesively bonded joints", Unpublished Doctoral Dissertation, Virginia Polytechnic Institute, USA,1998.

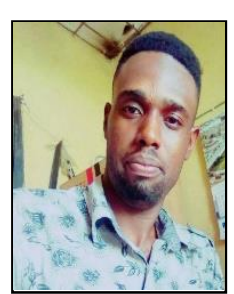

Okafor Chinedum Vincent was born in Nigeria. He obtained B.Sc in Building from Nnamdi Azikiwe University Nigeria in 2012. He is currently doing his M.Sc in Construction Technology in the same institution. His field of interest includes Computational Fluid Dynamics and Structural Design/Analysis. He has published a number of publications on different peer reviewed international research journals. 